\title{
MÁSCARAS GENOLÓGICAS: CAMÕES, PERSONAGEM DE NATÁLIA CORREIA (UMA LEITURA DE ERROS MEUS, MÁ FORTUNA, AMOR ARDENTE)
}

\author{
GENOLOGICAL MASKS: CAMÕES, \\ CHARACTER OF NATALIA CORREIA (A \\ READING OF ERROS MEUS, MÁ FORTUNA, \\ AMOR ARDENTE)
}

Jorge Vicente Valentim ${ }^{1}$

\section{RESUMO}

Partindo do conceito de "epicização", proposto por Barbalosi e Plana (2012), a proposta deste ensaio é a de apontar uma leitura da obra dramática Erros meus, má fortuna, amor ardente (1981), de Natália Correia. Camões comparece como protagonista da trama, tecida dentro da trajetória do poeta, de Lisboa ao degredo e, por fim, o seu retorno. Saindo da dinâmica do drama histórico - ainda que os fatos contextuais lá compareçam como uma forma de sublinhar as questões temáticas mais prementes -, Natália Correia, já a partir do título, estabelece um jogo de citações intertextuais com a finalidade de revelar as máscaras da sua personagem. A ideia, aqui, incide sobre a possibilidade de pensar cada um dos gêneros desenvolvidos pelo poeta português, apresentados ao longo da efabulação, como uma espécie de persona por onde o seu criador almejou destilar desde a amargura de um desconcerto consciente ao sofrimento das muitas dimensões amorosas: à(s) mulher(es) amada(s) e à pátria.

PALAVRAS-CHAVE: Epicização, Camões, Natalia Correia 


\section{ABSTRACT}

Starting from the concept of "epiczation", proposed by Barbalosi e Plana (2012), the objective of this essay is to point out a reading of the play Erros meus, má fortuna, amor ardente (1981), by Natália Correia. Camões appears as the protagonist of the plot, woven within the trajectory of the poet, from Lisbon to the exile and, finally, his return. Leaving aside the dynamics of historical drama - although the contextual facts there appear as a way of emphasizing the most pressing thematic issues -, Natalia Correia, already from the title, establishes a game of intertextual citations with the purpose of revealing the masks of her character. The idea here focuses on the possibility of thinking each of the genres developed by the Portuguese poet, presented throughout the dramatic piece, as a kind of persona where its creator sought to distil from the bitterness of a conscious disconcert to the suffering of many loved dimensions: to the beloved women and to the motherland.

KEY WORDS: Epiczation, Camões, Natália Correia.

Para Luci Ruas, mais uma vez e sempre, porque, pelas suas mãos, recebi, pela primeira vez, os versos camonianos, recitados, de memória, numa aula memorável e inesquecível. Rito de passagem e batismo de fogo, ouvindo o lamento do Adamastor, tive naquele momento a certeza do caminho a ser trilhado.

[...] todos os caminhos portugueses vão dar a Camões, de cada vez mudado consoante os olhos que o vêem, em vida sua braço às armas feito e mente às musas dada, agora de espada na bainha, cerrado o livro, os olhos cegos, ambos, tanto lhos picam os pombos como os olhares indiferentes de quem passa.

[JOSÉ SARAMAGO. O ano da morte de Ricardo Reis.]

Epicizar o teatro, portanto, não é transformá-lo em epopeia ou romance, nem torná-lo puramente épico, mas incorporar-lhe elementos épicos no mesmo grau que lhe incorporamos tradicionalmente elementos dramáticos ou líricos. Logo, a epicização [...] implica o desenvolvimento da narrativa sem ser uma simples narrativização do drama.

[LAURENCE BARBOLOSI e MURIEL PLANA.

"Epicização".]

Quando, em 1984, José Saramago trouxe à cena a trama de Ricardo Reis, heterônimo pessoano, transformado em protagonista do seu conhecido romance $O$ ano da morte de Ricardo Reis, reiterava o ficcionista contemporâneo um dos legados mais paradigmáticos e, ao mesmo tempo, preciosos aos leitores de língua portuguesa sobre a importância de Luís 
de Camões nas bases culturais, artísticas, políticas e sociais do seu país. A conhecida passagem, citada em epígrafe, sublinha exatamente o caráter incontornável da figura do poeta e de sua obra na cultura lusófona.

Eixo monumental, alicerce e linha mestra da literatura portuguesa, Luís de Camões reaparece em ressonâncias, ecos e revisitações intertextuais ao longo dos séculos de existência dos movimentos artísticos do seu país. Desde Bocage, Garrett até os escritores atuais, de acordo com Teresa Cristina Cerdeira, o autor de Os Lusíadas vem sendo relido de forma gradativa pelo cânone lusitano e de maneira mais pontual na contemporaneidade, num nítido "diálogo de textos, de uma conversa que os séculos não anulam, ao contrário, que o tempo parece sempre enriquecer em sua diversidade" (CERDEIRA, 2000, p. 226). Não à toa, autores como Almeida Faria, António Lobo Antunes, Frederico Lourenço, Jorge de Sena, o próprio José Saramago e, é claro, Natália Correia, dona de uma obra vasta e produtiva, sobretudo, no que toca à recuperação e à manutenção de uma memória cultural portuguesa, confirmam esta proposta de recriação e efabulação de Camões, enquanto criatura modelar para os artistas dos séculos XX e XXI.

Num dossier, portanto, dedicado a Camões, nada mais justo que trazer uma leitura da obra dramática de Natália Correia, Erros meus, má fortuna, amor ardente (1981), criada para celebrar, em 1980, o 4. Centenário da morte do autor d'Os Lusíadas, encomendada à escritora pelo Teatro Nacional D. Maria II.

Composta de três atos, a peça Erros meus, má fortuna, amor ardente traz um conjunto diversificado e extenso de personagens flutuantes durante toda a trama, distribuídos ao longo dos 18 diferentes quadros e cenas. São, ao todo, 44 personagens (D. Manuel, D. Fernando de Noronha, Pero de Andrade Caminha, D. Gonçalo Borges, dentre outros) e 21 figurações especiais, além de outros figurantes, cuja função principal é a de compor os cenários, ilustrando os contextos temporal e espacial de ocorrência na sequência cênica.

Tal dado poderia até parecer despercebido para a dramaturga, no entanto, esta difusão das vozes componentes da peça constitui um recurso fulcral para uma obra que procura explorar ao máximo alguns efeitos barroquistas na sua consecução, tais como a dimensão polifônica, a superposição labiríntica de discursos e nós estruturais e a ênfase numa sintaxe carregada de elementos do Quinhentismo português. Contudo, é preciso já frisar que não é sobre o espetáculo que proponho as reflexões seguintes, mas sobre o texto per se, procurando observar os recursos de composição tecidos na efabulação dramática nataliana.

Neste sentido, a pulverização de vozes ao longo da trama acaba por efetuar uma espécie de deslocamento sobre as personagens atuantes, em termos de recusa de uma hierarquia dispositiva nas suas aparições e relevâncias. Ainda que o foco recaia sobre a figura do poeta homenageado em 1980, parece que a autora aposta não numa construção exclusivamente 
histórica ou num impasse contextual específico, como ocorre, por exemplo, em O que farei com este livro? (1980), de José Saramago, onde o protagonista Luís de Camões vê-se numa batalha social, política e intelectual para publicar Os Lusíadas.

A ideia reside, sim, numa apropriação de momentos da obra camoniana e na recriação do impacto da recepção de sua obra no contexto quinhentista português, para, a partir desses aspectos, mostrar as máscaras genológicas possíveis para compreender a dimensão gigantesca que tem a obra do autor das Rimas. Tanto assim parece ser que, ao longo dos 18 quadros, escritos e dispostos quase como em forma de cantos - naquele sentido empregado para a subdivisão estrutural do poema épico -, a trajetória camoniana vai sendo gradativamente recuperada, procurando observar os dois eixos paradigmáticos da obra do poeta sugeridos no verso que dá título à peça: o desconcerto do mundo e o amor ["Erros meus, má fortuna, amor ardente" (CAMÕES, 1963, p. 536)].

Este sentimento desassossegado do poeta surge desde as primeiras cenas do Ato I: debatendo-se com um profundo sentimento de paixão entre duas personagens da corte portuguesa (D. Catarina de Ataíde e a Infanta D. Maria), a personagem Luís de Camões aparece como o poeta atormentado pelas dores de amores efetivamente não concretizados (afinal, a primeira é prometida a D. Francisco de Noronha e a segunda é a irmã do Rei D. Manuel), cujas falas deixam destilar as principais linhas de força de sua obra:

Luís de Camões: Que angélica figura! E diz-me o seu olhar suave que está tão firme em amar-me como eu em adorá-la.

D. Francisco de Noronha: Sempre hás-de pôr o desejo onde não deves.

Luís de Camões: Ponho-o onde o coração ordena. Como posso encontrar a estrela que o guia se o não elevar a altos firmamentos?

D. Francisco de Noronha: Para agarrares esta estrela mais te valera florear cavalos persas na Rua Nova.

Luís de Camões: Não os tenho. Para não vestir serguilha e saragoça mais me acode a vossa protecção do que a minha nobreza que é das que andam a tinir.

D. Francisco de Noronha: És filho de um Cavaleiro fidalgo.

Luís de Camões: Que há-de morrer à espera de ser rico. Mas é nesta pobreza que encontro a liberdade de ousar cousas que me incendeiam a fantasia. E no amor, D. Francisco, a fortuna só favorece os ousados. (CORREIA, 1981, p. 26-27)

O diálogo estabelecido entre as duas personagens revela um intenso jogo intertextual com a obra camoniana, na medida em que a fala do protagonista surge sempre eivada das principais linhas de força do seu projeto literário. Aqui, a revisitação ao soneto "Nunca em amor danou o 
atrevimento; / Favorece a Fortuna a ousadia" (CAMÕES, 1963, p. 542) já sugere a proposta de Natália Correia em pensar a relevância de Luís de Camões ligada necessariamente à sua poesia, como que indicando ao leitor/ espectador que só se poderá chegar ao entendimento daquele a partir da leitura e da compreensão desta. Tal ideia não aparece de forma gratuita porque a própria autora, em conferência no $11^{\circ}$. Congresso da Associação Internacional de Críticos de Teatro, em 1990, em Lisboa, já defenderia a tese de que "O teatro só morrerá quando morrer a poesia que é a sua matéria prima mesmo quando não transpareça. E chega o momento de a poesia ser chamada a desempenhar no teatro o papel de reveladora que lhe é inato" (CORREIA, 1992, p. 112, grifos meus).

Na obra dramática nataliana, portanto, a poesia desempenha um papel fundamental para a própria criação teatral, não havendo uma elipse ou um vácuo entre as duas categorias genológicas. Por isso, a voz do protagonista e sua atuação na trama vêm carregadas com o peso e com a relevância de sua obra poética.

Numa das cenas mais significativas, quando o protagonista Luís de Camões é desafiado pela Infanta, com o apoio de Pero de Andrade Caminha, a criar versos no sarau, ao sentir-se arrebatado pela beleza da irmã do rei, mesmo diante de Catarina de Ataíde, para quem já havia declarado os seus sentimentos, os textos da Lírica de Camões comparecem, ora observando os encantos desta última, ora insinuando uma paixão fulminante pela Infanta:

Pero de Andrade Caminha, para Luís de Camões: Já que te declaras nos teus versos tão apaixonado admirador dos olhos verdes, sobre eles vou dar-te um mote.

CATARINa, enternecida à parte: Olhos verdes? São os meus.

Pero de Andrade Caminha: Sois formosa e tudo tendes.

Senão que tendes os olhos verdes.

Luís de Camões leva o olhar a Catarina e depois desvia-o para a Infanta. Este movimento é seguido por todos, com a cabeça, à exceção da Infanta e da Mestra.

Luís DE CAMÕEs, para Catarina, seguido de todos os olhares que vão ao endereço do poema:

Tudo, Senhora, alcançais

Quanto ser formosa alcança;

Se não que dais esperança

Com os olhos com que matais.

Se acaso os alevantais

É para as almas renderdes...

Se não que tendes os olhos verdes.

Vota-se para a Infanta e póe grande intensidade no primeiro dístico. Todas as cabeças acompanharam o movimento de Luís de Camões.

Ouro e azul é a melhor

Cor por que a gente se perde.

Volta-se de novo para Catarina. O gesto percute-se nos que the vêm seguindo os movimentos. 
E se a graça desse verde

Tira a graça a toda a cor,

Ainda que sendo flor

A cor que nos olhos tendes,

Escondei-os, pois que são verdes.

Palmas com cochichos que sublinham a intenção do poema. Quando ouve a exaltação do ouro e do azul, Catarina leva as mãos ao rosto para esconder as lágrimas. Terminada a recitação, fez menção de se retirar. (CORREIA, 1981, p. 44-45)

A partir da sequência desencadeada com a cena acima, títulos dos sonetos, como "Num tão alto lugar, de tanto preço", "Crescei desejo meu, pois que a ventura", "Aquela triste e leda madrugada" (CAMÕES, 1963, p. 542, 529 e 272); bem como das redondilhas, "Sois formosa, e tudo tendes / Senão que tendes os olhos verdes", e "Perdigão que o pensamento / Subiu em alto lugar" (CAMÕES, 1963, p. 644 e 478) são trazidos à cena com a finalidade não só de revisitar a obra do poeta, mas também de as recontextualizar, na medida em que apontam para uma nova dimensão temporal, para além daquela do seu próprio cenário de criação. E não será exatamente este o papel de "revelação do caminho para um verdadeiro real humano" (CORREIA, 1992, p. 112) que caberia à poesia camoniana dentro de uma obra teatral sobre a figura do poeta, tal como propõe Natália Correia?

Esta invasão da dimensão lírica dentro do corpo dramático acaba por revelar a primeira máscara genológica do poeta, posto que, exatamente na poesia lírica, encontrou Camões o seu porto seguro e a sua Ilha dos Amores. No entanto, parece ser no embate de amores não concretizados, mas almejados pela "virtude do muito imaginar" (CAMÕES, 1963, p. 301), que a personagem se encontra. Isto irá se confirmar, por exemplo, no Ato II, quando, já no degredo em Goa, é instado a criar uma peça para celebrar os grandes feitos do Vice-Rei Francisco Barreto. No seu lugar, porém, o poeta oferece o Auto de Filodemo, cujos trechos são literalmente citados ao longo deste espetáculo, encenado dentro do próprio drama, causando uma revolta no pretenso homenageado, já que este percebe que a obra posta em cena constitui "um estratagema de que o autor se serviu para exibir amores intoleráveis” (CORREIA, 1981, p. 115).

$\mathrm{Na}$ verdade, a personagem dribla as exigências da celebração e metaforiza, como dirá a personagem Heitor da Silveira, a "sua maluqueira pela Infanta no auto que dedica ao Vizo-Rei” (CORREIA, 1981, p. 110), deixando em evidência outra máscara genológica de Luís de Camões vir à cena: a do dramaturgo. Assim, do pretendido retorno a Lisboa, o leitor depara-se com um protagonista amargurado diante de um castigo ainda maior: a sua nomeação como "Provedor-Mor dos Defuntos e Ausentes nas partes da China” (CORREIA, 1981, p. 116).

A partir daqui, outros textos da obra camoniana são convocados a fim de encenar as dores e os desconcertos do mundo do protagonista: os sonetos "Ah, minha Dinamene! Assim deixas-te / Quem nunca deixar pode de querer-te?" e "Erros meus, má fortuna, amor ardente" (CAMÕES, 1963, p. 524 e 536) e os versos d'Os Lusíadas constituem as duas outras máscaras 
genológicas camonianas recuperadas ao longo do Ato II: a lírica e a épica. Se, por um lado, estes últimos configuram aquela "mesma linha de consideração do modelo do drama histórico", reiterando, portanto, "a tentativa de criação de cor local, conseguida quer pela construção de uma língua próxima da do séc. XVI [...] quer pelas precisas indicações cénicas no que diz respeito à indumentária e atitudes das personagens, a efeitos especiais de cena e a adereços." (BRILHANTE, 1983, p. 83), não se poderá negar que eles deixam em evidência o próprio processo de criação poética, na medida em que, gradativamente, o leitor começa a vislumbrar no texto a máscara épica da personagem-poeta que, com uma imaginação pulsante e constante, vai conduzindo sua pena num exercício literário em que o exercício épico não exclui as tensões dramáticas e líricas, antes, todas elas parecem conviver e convergir para o ato máximo de criação.

Aqui, gosto de pensar que a mão da autora surge como uma espécie de guião, conduzindo o leitor/espectador a entender o processo de simbiose e de revelação que a obra poética exerce sobre a figura de seu protagonista. Tanto assim parece ser que, mais do que personagens de uma epopeia, o Coro das Mulheres, os Navegantes, o Velho do Restelo, o Mostrengo, Vasco da Gama e a Infanta-Vênus ressurgem na peça nataliana como avatares de um drama que mais se aproxima das ambiguidades, da estética labiríntica e dos paradoxos maneiristas do que propriamente do contexto cultural renascentista.

Neste sentido, vale sublinhar que, no Ato III, já reposicionado na corte lisboeta, depois de anos no exílio, o poeta depara-se, primeiramente, com um júri censorial que propõe um retalho ao texto original d'Os $\mathrm{Lu}$ síadas, a que o seu autor recusa com firmeza e, ao mesmo tempo, sutileza. Em seguida, surge um D. Sebastião ávido por vitórias e glórias, parecendo esquecer completamente aquele presságio lançado pela personagem Velho do Restelo: "A alma desta jornada não é só o ardor patriótico. Trata-se de uma guerra santa. Espanha e Portugal são a melhor e a maior parte da Cristandade" (CORREIA, 1981, p. 200). O desfecho, como todos sabem, é a derrota do monarca nos campos de batalha de Alcácer-Quibir e a junção dos dois reinos, sob o comando da dinastia filipina.

Ora, mais do que espectador da história do seu tempo, parece o protagonista, já nas cenas finais, nutrir a necessidade de expor o forte sentimento de consciência de que, no contexto português, sua obra teve uma repercussão capaz de afetar não apenas as vidas particulares dos seus contemporâneos, mas também a trajetória política da própria nação. Tanto que, ao saber da morte de D. Sebastião e prevendo os caminhos delicados do futuro político português, a personagem declara em sua última aparição em cena:

Luís de Camões: Matei-o eu. Em criminosos versos incitei-o a estremos que são a abreviada destruição do que pretendem. Os meus cantos inscientes ganharam asas negras num anjo maligno. Jaz morto. Seus olhos espantados, na íris de um sonho delirante, apodrecem numa lama de sangue. $\mathrm{O}$ trono está vazio. Para o ocupar já os tiranos passam as águas do Guadiana. O meu coração não pode mais com o remorso. 
Ó musas perversas! Deste louco amante da Pátria vos servistes, para lhe dar, em génio, o canto da sereia que havia de arrastá-la para a morte. Ó Pátria ferida por meus excessos de filho desastradamente extremoso! Por isso me fazes contar os dias por desgraças. Por isso me engeitas. Perdoa-me. Na febre amorosa pode o amante magoar a amada. E o meu crime foi amar-te demais. Abre-me o seio. Ao menos na morte. Pouco espaço ocupa o cadáver de um filho desgraçado. [...] Vou morrer. E verão todos que fui tão afeiçoado à minha Pátria que não só me contentei de morrer nela mas com ela. (CORREIA, 1981, p. 231-232)

Se, antes de cair o pano, o poeta procura expressar, nas suas últimas falas, a consciência dos seus erros, de sua má fortuna e do amor ardente que também sentia pela Pátria, a derradeira cena parece apontar não apenas para o surgimento do mito sebastianista, naquela ausência/presença fantasmática do monarca morto nos campos de batalha, mas também para a continuidade de uma outra instância mítica, em que o autor d'Os Lusíadas figuraria como seu agente principal. Isto porque, logo após o vaticínio da personagem 2a Mulher do Povo ["Possa a nossa dor ressuscitar o Rei para que ele perpetue o nosso sangue” (CORREIA, 1981, p. 235)], não é a figura de D. Sebastião ou a sua sombra ou mesmo uma sugestão imagética sua que permanece em cena como o grande motivador desta fala, mas o próprio Luís de Camões, conforme indica a última rubrica do texto: "Ao fundo, em contra-luz, a silhueta de Luís de Camões funde-se num clarão que, entretanto, se foi acendendo. A imagem transmite a idéia da transformação das misérias terrenas do Poeta na espécie luminosa da sua imortalidade" (CORREIA, 1981, p. 233).

Diante, portanto, do que até aqui expus, cabe-me, agora, já em caráter conclusivo, pensar esta peça de Natália Correia como uma das obras capazes de dialogar diretamente com aquele efeito de "epicização", defendido por Laurence Barbolosi e Muriel Plana, na medida em que, para além da possibilidade de incorporar elementos genológicos de outras manifestações textuais (o lírico, o épico e o epistolográfico) - conforme elucidado na epígrafe -, Erros meus, má fortuna, amor ardente também

testemunha conflitos entre interesses, classes, nações, ideologias, e lembra ao espectador [/leitor] os sofrimentos e as ações dos indivíduos medianos, põe em cena seus gestus: [...] eles são confrontados com a história e inseridos em problemáticas econômicas, sociais e políticas. (BARBALOSI e PLANA, 2012, p. 77)

Em meu entender, tal processo pode ser compreendido na peça nataliana, na medida em que chama a atenção para a sensibilidade do leitor/espectador, que se depara não apenas com um drama histórico, situado no século XVI, mas com um drama humano que diz respeito ao homem, ao sujeito e ao próprio ser português, recolocado agora quatro séculos depois da voz do poeta. Em outras palavras, parece Natália Correia eleger não somente Luís de Camões como o grande protagonista de sua peça, mas também a sua obra, sob múltiplas máscaras genológicas, unindo-os sim- 
bioticamente. Com isto, a escritora aposta numa espécie de atemporalidade da pena camoniana, revigorando as ideias do desconcerto e do amor como dois eixos pendulares da própria existência humana.

Por isso, ainda que respeite a leitura operada por Maria João Brilhante, permito-me dela divergir em virtude de que aquela "relacionação do geral e do particular, já de si arriscada", não é aqui "prejudicada pela verbosidade quase geral das personagens, pelo nível de língua literário e pelo conhecimento prévio de muitas das situações do texto" (BRILHANTE, 1983, p. 83), como faz crer a sensível leitora do teatro de Natália Correia. Ao contrário, exatamente porque o dramático permite um amplo espaço de entrada, diálogo citacional e convívio no seu bordado com todas estas manifestações, em meu entender, não existe uma sobreposição de qualquer categoria genológica sobre a principal. Aquilo a que a ensaísta portuguesa designa como "distração", "quer da análise histórica quer da intriga, para seguir a melodia, ou, talvez melhor, o canto que constitui este texto de Natália Correia" (BRILHANTE, 1983, p. 83), na verdade deve e pode ser entendido como uma transformação da ficção, da efabulação dramática, em reflexão, como se compreende o processo de epicização (BARBALOSI e PLANA, 2012), dentro do Léxico do Drama Moderno e Contemporâneo.

Neste sentido, tem razão Duarte Ivo Cruz, ao analisar Erros meus, má fortuna amor ardente como uma obra dramática que "enquadra o Barroco numa visão imaginosa e exuberante de Camões e realça uma sublimação da intervenção popular, transformada e organizada em coro de tragédia" (CRUZ, 2001, p. 299), realçando, portanto, aquele projeto de entender o diálogo do teatro clássico e de seus principais nomes com a própria atualidade do mundo contemporâneo, tão almejado por Natália Correia (1992).

Ainda que a concepção barroca seja uma marca latente na produção dramática de Natália Correia, aspecto que aqui não detalhamos em virtude do limite que um ensaio impõe e da proposta do dossier, vale destacar o trabalho detalhista e criterioso da autora e de Fernando Ribeiro de Mello, responsável pela edição de Erros meus, má fortuna, amor ardente. Sob a chancela da editora Afrodite, o exemplar físico da peça nataliana comporta não apenas o texto da autora, mas vem enriquecido com imagens de Ângelo, Calvet, Cruzeiro Seixas, Lima de Freitas, Relogio, Resende, Paulo-Guilherme, da própria Natália Correia, além dos apontamentos de Jacinto Ramos sobre a encenação e de Paulo Guilherme sobre os cenários, os figurinos e a estrutura plástica do espetáculo, e uma reprodução do tema musical principal de César Batalha. Trata-se, na verdade, de uma materialização com toques barroquistas do texto e da produção do espetáculo, realizada ainda em vida pela própria Natália Correia.

Por fim, em Erros meus, má fortuna, amor ardente, os elementos do grande elenco literário produzido por Luís de Camões parecem estar categorizados como "descontinuidade, distância, mensagens, reflexividade" (BARBALOSI e PLANA, 2012, p. 78), possibilitando ao leitor a oportunidade de "decifrar o sentido dessa fábula, dessa parábola" (BARBALOSI e PLANA, 2012, p. 78). No caso específico da obra nataliana, um deles, como 
bem parece apontar a última rubrica, refere-se à "espécie luminosa da sua imortalidade" (CORREIA, 1981, p. 235), bem como da atemporalidade dos versos camonianos. Se não podemos, simplesmente, encerrar o legado do autor d'Os Lusíadas nas paredes temporais quinhentistas, também não devemos deixar de observar, como bem ensinou Cleonice Berardinelli, que "a Literatura Portuguesa antiga é a base de tudo. Nós chegamos até aqui porque existiu lá atrás um sujeito chamado Camões" (BERARDINELLI, 2015).

Por isso, acredito eu, que, quase 450 anos depois de sua morte, ainda estamos aqui a celebrar a obra e o legado deste grande escritor. Bem-haja.

\section{REFERÊNCIAS BIBLIOGRÁFICAS}

BARBALOSI, Laurence e PLANA, Muriel. Epicização. In: SARRAZAC, Jean-Pierre (org.). Léxico do Drama Moderno e Contemporâneo. Tradução de André Telles. São Paulo: Cosac \& Naify, 2012, p. 76-79.

BERARDINELLI, Cleonice. Ensinar é preciso. Entrevista à Revista de História. Disponível em < http://www.revistadehistoria.com.br/secao/entrevista/cleonice-berardinelli >. Acesso em 11 de setembro de 2016.

BRILHANTE, Maria. Recensão crítica à Erros meus, má fortuna, amor ardente. Colóquio / Letras 73. Lisboa: Fundação Calouste Gulbenkian, p. 82-83, 1983.

CAMÕES, Luís de. Obra completa. Rio de Janeiro: Companhia Aguilar Editora, 1963.

CERDEIRA, Teresa Cristina. O avesso do bordado. Ensaios de literatura. Lisboa: Caminho, 2000.

CORREIA, Natália. A vingança das Euménides e o teatro actual. In: SERÔDIO, Maria Helena. O teatro e a interpelação do real. Lisboa: Colibri, 1992, p. 109-112.

Erros meus, má fortuna, amor ardente. Lisboa: Afrodite, 1981.

CRUZ, Duarte Ivo. História do teatro português. Lisboa: Verbo, 2001.

SARAMAGO, José. O ano da morte de Ricardo Reis. São Paulo: Companhia das Letras, 2011.

Recebido para publicação em 20/01/19

Aprovado em 03/02/19

\section{NOTAS}

1 Doutor em Letras Vernáculas (Literatura Portuguesa) pela Faculdade de Letras da UFRJ. Professor Associado do Departamento de Letras e Professor Permanente do PPGLit/UFSCar. Professor Colaborador do PPGEL - UNESP/FCLAr. O presente texto é resultante de pesquisa realizada com financiamento FAPESP (Processo 2017/05990-0). 